\title{
The gelsluice, an innovative idea for the present sluice structures
}

\author{
Jacob Gerrit (Jarit) de Gijt ${ }^{1,2^{*}}$ and Bob Heester $^{3}$ \\ ${ }^{1}$ Hydraulic Structures and Flood Risk Section, Delft University of Technology, Delft, the Netherlands \\ ${ }^{2}$ Rotterdam Engineering Department, Rotterdam, the Netherlands \\ ${ }^{3}$ Antea Group, Rotterdam, the Netherlands
}

\begin{abstract}
Sluices have been built worldwide since in 984 when the first sluice was built in China to speed up the operations in the Grand canal. Since that time different types of sluices have been developed world wide both in size and material use and their own shipping and structural characteristics. One of the main drawbacks of the present sluice designs is the waiting time. This problem of the waiting time is in principle overcome by the design of the gelsluice (gellock). This paper describe the development of sluices construction in general and with the emphasis on the characteristics of the innovative gelsluice. A preliminary design of the gelsluice will be discussed and presented. Finally some recommendations are presented for further research to improve the design of the gelsluice.
\end{abstract}

\section{Introduction}

Sluices are important civil engineering structures to cope with water level differences and to ease shipping. Since the first sluice was built in China along the Grand canal several types of sluices have been developed. This paper will give a brief overview of the existing types of sluices.

The great disadvantage of most of the present sluice designs is that ships have to wait to pass the sluice. However this is depending of the height difference to overcome a time consuming operation. These disadvantages are overcome with the design of the gelsluice. This paper will discuss the design aspects of gelsluice and will indicate what is necessary to make this type of sluice operational.

\section{History of sluice design development}

The oldest shipping lock was constructed in China for the Grand Canal in 984. Before that time, the canal was divided in sections by dams to control the water levels and slipways consisted mostly of a row of trees over which the ships were pulled over the dam to the other part of the canal .This caused a considerable of damage to shipping. In Europe, the first lock was introduced in the Netherlands, Vreeswijk in 1358. This construction was a socalled pounded lock with guillotine doors. Recently an old lock with the guillotine doors in

\footnotetext{
*Corresponding author: j.g.degijt@tudelft.nl
} 
the Rotte River near Rotterdam has been rebuilt. This has been made possible by scanning at location, which revealed enough information for rebuilding. At this moment the biggest lock of the world is in Kallo, Belgium.

The gelsluice idea was first developed in the summer of 2011. That time the idea was made to close the Nieuwe Waterweg, the entrance of the port of Rotterdam by a dam of gel as this might be needed due to sea level rise. The great advantage of this type of sluice is that it has no doors so that creates the possibility that ships can pass the sluice without waiting time. Several options and locations have been considered but finally the selected location was the Nieuwe Waterweg as presented in Figure 1.



Fig. 1. Location of the gelsluice.

\section{The development of gelsluice}

The development of the gelsluice after the first idea was made possible by students of Hogeschool of Rotterdam as they investigate different gel compositions and carried out hydraulic testing in the laboratory. Finally the gel which was found the best was a mixture of and gelatine and barit which was added to increase the density of the gel. The physical parameters are presented in Table 1.

The original sketch Figure 2 indicates the principal of the gelsluice which consists of a dam made of mixture of gelatine and barit. The gelsluice consists of a dam made of gelatine and barit with approximately a density of $11 \mathrm{~kg} / \mathrm{m}^{3}$. The mixture has been selected after testing of several other mixtures. From this mixture a dam has been built in a hydraulic flume to test the behaviour of the passing ships and the gel. The original sketch is displayed in Figure 1, which finally involved to the design of the geldam as given in Figure 3.

This idea evolved in the dimensions as presented in Figure 3 which takes into account the results of laboratory testing to find the required properties.

Of course also attention must be paid to the forces on the ship, see Figure 4 when passing the gel as the upward force on the ship in the gel differs from that in water its necessary to have a slope of 1:6 to prevent the development of high stresses in the ships hull.

The ships are pulled through the sluice in the same manner as used in Panama Canal. This is required as the motors are not yet in able to cool the machinery when the ship is in the gelsluice. The gelsluice principally does overcome all the drawbacks of existing sluices. There is no waiting time and hardly any mechanical equipment is required. The gel itself settles and must be maintained and thus a gel suppletion plant is included in the plan. As the gelsluice is impermeable for water the sluice complex should facilitate that the flow of 
the river is not blocked and that fish passage is possible That result in the design as displayed in Figure 6. The gelsluice also prevent salt water intrusion.

Table 1. Summary of physical parameters of gel.

\begin{tabular}{|l|l|l|}
\hline \multicolumn{1}{|c|}{ Parameter } & \multicolumn{1}{c|}{ Value } & \multicolumn{1}{c|}{ Unit } \\
\hline Specific weight & 1100 & $\mathrm{~kg} / \mathrm{m}^{3}$ \\
\hline Viscosity & 0,0605 & $\mathrm{mPa} / \mathrm{s}$ \\
\hline Kinematic Viscosity & $5,5^{*} 10^{-5}$ & $\mathrm{~m}^{2} / \mathrm{s}$ \\
\hline Friction angle & $\max 1$ & degrees \\
\hline Maximum slope & $1: 60$ & $1: \mathrm{m}$ \\
\hline Maximum shearstress & 1,04 & $\mathrm{~N} / \mathrm{mm}^{2}$ \\
\hline Minimal required shear stress & 0,13 & $\mathrm{~N} / \mathrm{mm}^{2}$ \\
\hline Permeability & $<10^{-10}$ & $\mathrm{~m} / \mathrm{s}$ \\
\hline
\end{tabular}

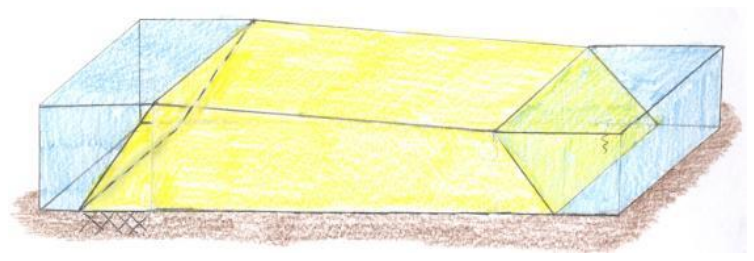

Fig. 2. Original sketch of the gelsluice.

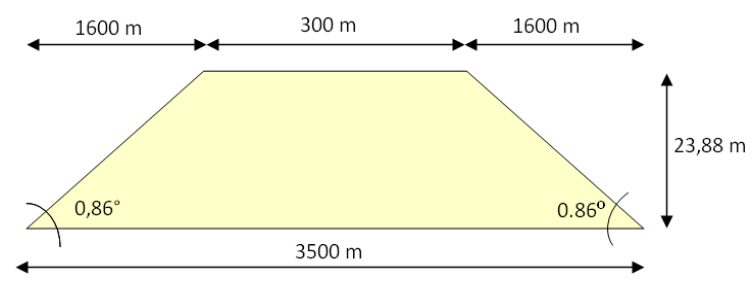

Fig. 3. Shape of geldam.

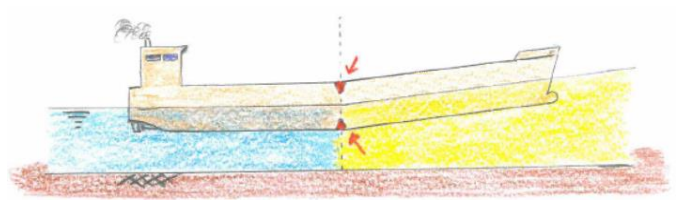

Fig. 4. Indication of influence of density change on the ships hull. 


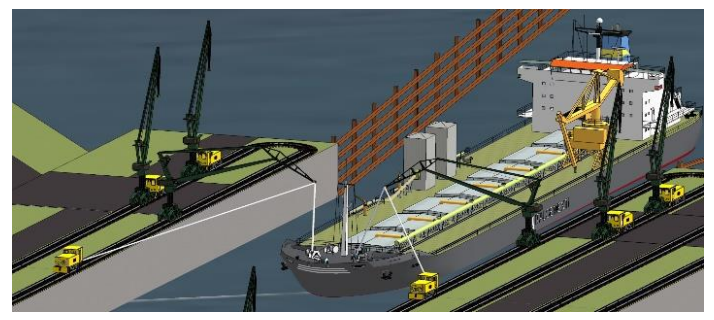

Fig. 5. Ships are pulled through the gelsluice.

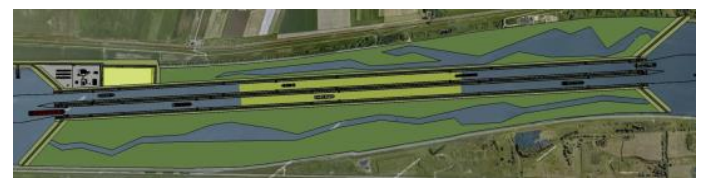

Fig. 6. Layout of the gelsluice complex.

\section{Costs}

In Table 2 a brief cost comparison is presented which indicates that the gelsluice is more expensive then a traditional sluice. However, it is anticipated when the whole life cycle and operation costs are included the gelsluice is more advantigious. The gelsuice shall to be more favourable espicially due the reduction of the waiting time of ships passing the gelsluice.

Table 2. Cost comparison.

\begin{tabular}{|l|c|c|}
\hline \multicolumn{1}{|c|}{ Project } & Costs (€) in million & \% van gelsluice \\
\hline Maeslantkering & 700 & 54 \\
\hline Nieuwe sluizen Ijmuiden & 700 & 54 \\
\hline Gelsluis & 1295 & 100 \\
\hline
\end{tabular}

\section{Conclusions and recommendations}

The gelsluice principally does overcome all the drawbacks of existing sluices. However more research is required to improve the gel characteristics. Thereby the following points have to be considered: the behavior of the gel in the long term, the settling, stability behavior of the gel with time, the behavior of ships within gel. Also the cost aspects, the gel production and recycling should be investigated.

This implies that the main research question is the combination of classical hydraulics with the phenomena of hydraulic aspects of pumping fluids to understand and predict the behavior of the gel.

\section{References}

1. B. Heester, N. Reijmers, Joolingen van M., Gelsluis, B.Sc. Thesis, Hogeschool Rotterdam (2011) 
2. J.G. de Gijt, Interview cobouw (2011)

3. P.H.J.M. van Gelder, N. Doorn, J.G. de Gijt, Chapter: Responsible innovation in the hydraulic engineering sector in New perspectives on responsible innovation, by Hoven van der D. et al. (2018) 